\title{
Mesoporous Activated Carbon Supported Ru Catalysts to Efficiently Convert Cellulose into Sorbitol by Hydrolytic Hydrogenation
}

\author{
Fatima-Zahra Azar*, M. Ángeles Lillo-Ródenas $(\mathbb{1}$ and M. Carmen Román-Martínez *(1) \\ MCMA Group, Department of Inorganic Chemistry and Materials Institute, Faculty of Sciences, \\ University of Alicante, Ap. 99, E-03080 Alicante, Spain; mlillo@ua.es \\ * Correspondence: fz.azar@gmail.com (F.-Z.A.); mcroman@ua.es (M.C.R.-M.)
}

Received: 17 July 2020; Accepted: 24 August 2020; Published: 26 August 2020

\begin{abstract}
Catalysts consisting of $\mathrm{Ru}$ nanoparticles $(1 \mathrm{wt} \%)$, supported on mesoporous activated carbons (ACs), were prepared and used in the one-pot hydrolytic hydrogenation of cellulose to obtain sorbitol. The carbon materials used as supports are a pristine commercial mesoporous AC (named SA), and two samples derived from it by sulfonation or oxidation treatments (named SASu and SAS, respectively). The catalysts have been thoroughly characterized regarding both surface chemistry and porosity, as well as Ru electronic state and particle size. The amount and type of surface functional groups in the carbon materials becomes modified as a result of the Ru incorporation process, while a high mesopore volume is preserved upon functionalization and Ru incorporation. The prepared catalysts have shown to be very active, with cellulose conversion close to $50 \%$ and selectivity to sorbitol above $75 \%$. The support functionalization does not lead to an improvement of the catalysts' behavior and, in fact, the $\mathrm{Ru} / \mathrm{SA}$ catalyst is the most effective one, with about $50 \%$ yield to sorbitol, and a very low generation of by-products.
\end{abstract}

Keywords: Ru nanoparticles; activated carbon; one-pot hydrolytic hydrogenation; cellulose conversion; sorbitol

\section{Introduction}

Concerns on the climate change explain the increasing interest of researchers in low carbon fuels and sustainable energy, which has boosted the investigation on the production of biofuels and chemicals from renewable feedstocks like biomass [1,2]. One of the most attractive approaches is based on the use of non-food biomass, whose conversion into valuable chemicals has recently become the object of study for many researchers dealing with biorefinery processes [1,3-5], and with related reactions such as hydrolysis, pyrolysis, fermentation, dehydration, hydrogenation, etc. A big effort is being made in this field in order to convert cellulose into sugar alcohols. Among these compounds, sorbitol is attractive because of its large number of applications: in pharmacies, food, cosmetics, and as an alternative for biofuel production [6-8]. This polyol can be obtained by two consecutive reactions: hydrolysis of cellulose to produce glucose, followed by glucose hydrogenation to sorbitol, meaning that the process requires two different catalytic functions. In fact, it is usually carried out with catalytic systems consisting of mineral liquid acids (like $\mathrm{H}_{2} \mathrm{SO}_{4}$ or $\mathrm{HCl}$ ) as hydrolysis catalysts, and supported metals with activity in hydrogenation reactions $[9,10]$. However, liquid acids are considered not to be green options, because of their corrosive properties and because they cannot be reused. Stable acidic solids are an interesting alternative because they can be easily recovered from the liquid media [11,12], diminishing its contamination, and they can, potentially, be reused. Because of that, they can be considered promising catalysts that could replace liquid acids to make the processes greener. 
This is the context of this proposal, which focuses on the use of heterogeneous bifunctional catalysts to obtain sorbitol from cellulose by the combined reaction known as hydrolytic hydrogenation. A suitable heterogeneous catalyst must be composed of a solid acid and supported metal particles to enhance, respectively, cellulose hydrolysis and the hydrogenation of hydrolysis products. Examples of recent works dealing with this topic are shown in references [13-16].

Considering the simultaneous need of acidic and metallic active sites for this approach, it is necessary to focus on a solid able to bear both acidic functional groups and metal nanoparticles on its surface. Carbon materials can easily be such a solid because both the surface area and the surface chemistry can be tuned in order to suit their properties to the desired application. In particular, acidic sites can be created without detriment of the textural properties. Besides, it has been fully recognized that they have outstanding properties as catalyst supports in many reactions $[17,18]$.

Among the metals active for the target reaction, Ru and Ni have proven to be very interesting $[10,19,20]$. In fact, this combination, catalysts based on carbon supported $\mathrm{Ru}$ and $\mathrm{Ni}$ metallic particles has been studied before, showing outstanding results. For example, Komanoya et al. reported $68 \%$ sorbitol yield with a $\mathrm{Ru}$ /active carbon (AC) catalyst and a mix milling process [21], and Deng et al. also reported $69 \%$ sorbitol yield with Ru supported on carbon nanotubes (CNT), but using a concentrated $\mathrm{H}_{3} \mathrm{PO}_{4}$ solution for cellulose pretreatment [22]. More recently, Ribeiro et al. reported $86 \%$ sorbitol selectivity, also using mix milling and Ru-Ni bimetallic catalysts supported on AC and CNT [23].

The present work deals with the preparation and characterization of Ru catalysts supported on activated carbons for the hydrolytic hydrogenation of cellulose. The pristine selected activated carbon is a commercial one, named SA, interesting mainly for its developed mesoporosity. Two further supports, named SASu and SAS, have been prepared from SA by sulfonation and oxidation treatments, respectively, with the purpose of increasing the carbon acidity. The relatively high mesoporosity of these carbon supported Ru catalysts is expected to facilitate the access of cellulose to the catalyst's surface, thus enhancing the interaction with the active sites, particularly acidic sites that catalyze cellulose hydrolysis. According to the research work of Chung et al. [24], the adsorption and transformation of $\beta$ - $(1 \rightarrow 4)$-glucans can be enhanced in the pores of a mesoporous carbon material, where the long cellulose chains can be more easily hydrolyzed to glucose monomers.

\section{Materials and Methods}

\subsection{Catalysts Preparation and Characterization}

The commercial powder activated carbon SA-30 from MeadWestvaco (USA) was used for this study, with abbreviated name SA. It was submitted to the following chemical treatments: A- $1 \mathrm{M}$ $\mathrm{H}_{2} \mathrm{SO}_{4}$, and B- $\left(\mathrm{NH}_{4}\right)_{2} \mathrm{~S}_{2} \mathrm{O}_{8}$ saturated solution in $1 \mathrm{M} \mathrm{H}_{2} \mathrm{SO}_{4}$. In both treatments, the $1 \mathrm{~g}$ carbon/10 mL solution mixture was stirred for $24 \mathrm{~h}$ at room temperature. Afterwards, the solid was recovered by filtration and washed several times with distilled water (up to the total elimination of sulfates in the filtrate (determined by $\mathrm{BaCl}_{2}$ testing)). The samples resulting from these treatments are named as SASu and SAS, respectively.

$\mathrm{Ru}$ nanoparticles were supported on the carbon samples (SA, SASu and SAS) as follows: each degasified carbon sample $\left(150{ }^{\circ} \mathrm{C}, 4 \mathrm{~h}\right.$, vacuum) was put in contact with a $\mathrm{RuCl}_{3}$ aqueous solution ( $1 \mathrm{~g}$ carbon/10 $\mathrm{mL}$ solution) of the appropriate concentration to obtain $1 \mathrm{wt} \%$ Ru loading, and kept under stirring for $14 \mathrm{~h}$ at room temperature. Afterwards, the mixture was stirred in an ultrasound bath for $3 \mathrm{~h}$. Finally, the solvent was removed at $60^{\circ} \mathrm{C}$ for $10 \mathrm{~h}$, and then it was dried at $110{ }^{\circ} \mathrm{C}$ for $24 \mathrm{~h}$. Before being used in a catalytic activity test, the Ru containing samples, named $\mathrm{Ru} / \mathrm{SA}, \mathrm{Ru} / \mathrm{SAS}$ and $\mathrm{Ru} / \mathrm{SASu}$, were submitted to a reduction treatment under $\mathrm{H}_{2}$ flow $(80 \mathrm{~mL} / \mathrm{min})$, at $250{ }^{\circ} \mathrm{C}$ for $4 \mathrm{~h}$.

Preparation conditions have been selected after previous, still unpublished, works.

The textural properties of the original and $\mathrm{Ru}$ containing carbon materials were determined by $\mathrm{N}_{2}$ adsorption-desorption at $-196{ }^{\circ} \mathrm{C}$ (Autosorb-6B, Quantachrome). The specific surface area $\left(\mathrm{S}_{\mathrm{BET}}\right)$ and the total micropore volume $\left(\mathrm{V}_{\text {micro }}\right)$ were determined from $\mathrm{N}_{2}$ adsorption data by applying 
the Brunauer-Emmett-Teller (BET) and the Dubinin-Radushkevich (DR) equations, respectively. To estimate the mesopore volume $\left(\mathrm{V}_{\text {meso }}\right)$, the difference of the volume of $\mathrm{N}_{2}$ adsorbed as liquid at $\mathrm{P} / \mathrm{P}_{0}=0.9$ and $\mathrm{P} / \mathrm{P}_{0}=0.2$ was calculated $[25,26]$.

The surface chemistry of the prepared catalysts was studied by temperature programmed desorption (TPD) experiments in the following conditions: the sample (9-12 mg) was heated at $20^{\circ} \mathrm{C} / \mathrm{min}$ in He flow $(100 \mathrm{~mL} / \mathrm{min})$ up to $900^{\circ} \mathrm{C}$. The equipment used was a thermobalance (TA-SDT Q600) coupled to a mass spectrometer (Thermostar, Balzers), allowing the simultaneous record of weight loss and the analysis of evolved gases $\left(\mathrm{CO}_{2}, \mathrm{CO}\right.$, and $\left.\mathrm{H}_{2} \mathrm{O}\right)$ during the experiment.

Transmission electron microscopy (TEM, JEOL JEM-2010), with the Infinity Analyze software for image analysis, was used to analyze the size and distribution of the supported Ru particles.

X-ray photoelectron spectroscopy (XPS, VG Microtech Multilab ESCA-3000 spectrometer) was used to characterize the surface chemical composition and the electronic state of Ru in the prepared catalysts.

\subsection{Cellulose Hydrolytic Hydrogenation}

The commercial Avicel microcrystalline cellulose (99\%, Sigma Aldrich) was ball-milled (agate balls/cellulose weight ratio of $3500 \mathrm{rpm}$, with reverse rotation every $60 \mathrm{~min}$, for $7 \mathrm{~h}$ ). Catalytic tests were carried out in a $50 \mathrm{~mL}$ stainless steel Parr reactor (Model 4792) lined with a Teflon container, and equipped with a manometer and a thermocouple (see Figure S1 (S accounts for Supplementary Material)), as follows: $500 \mathrm{mg}$ milled cellulose, $125 \mathrm{mg}$ catalyst and $25 \mathrm{~mL}$ distilled water, together with a magnetic rod, were introduced in the reactor. After closing the reactor, it was purged several times to remove air, and then, it was filled with $\mathrm{H}_{2}$ and heated, under stirring, to reach the reaction conditions of 50 bar and $190^{\circ} \mathrm{C}$. The reaction time was $3 \mathrm{~h}$ in all catalytic tests. Reaction conditions have been selected after previous, still unpublished, works. To determine the reaction progress, the solid and liquid phases were separated by filtration, after cooling down, and then, the liquid phase was analyzed by high performance liquid chromatography (HPLC, 1200 infinity Agilent Technologies Hi-Plex Ca (Duo), $300 \times 6.5 \mathrm{~mm}$. An example of the obtained spectra is shown in Figure S2. The remaining solid (catalyst and unreacted cellulose) was dried and weighted to calculate the cellulose conversion.

The products yield was calculated from HPLC results, as indicated in Equation (1):

$$
\text { Yield }(\text { to } \mathrm{A})=((\text { Mol of } \mathrm{A}) /(\text { Mol of charged cellulose })) \times 100
$$

Conversion was calculated as shown in Equation (2):

$$
\text { Conversion }=(1-(\text { Weight of unreacted cellulose }) /(\text { Weight of charged cellulose })) \times 100
$$

Moreover, selectivity was calculated in terms of conversion and yield as follows (Equation (3)):

$$
\text { Selectivity }=(\text { Yield } / \text { Conversion }) \times 100
$$

\section{Results}

\subsection{Textural Properties}

The $-196{ }^{\circ} \mathrm{C} \mathrm{N}_{2}$ adsorption-desorption isotherms are presented in Figure S3. They are type IV according to the IUPAC classification [27]. The relatively high adsorption at low relative pressure and the steep slope indicates that these materials contain significant volumes of both micro and mesopores.

The textural parameters calculated from the isotherms data are shown in Table 1. Carbon SA presents high surface area and pore volume, with a similar proportion of micro and mesopore volumes. Treatment $\mathrm{A}\left(1 \mathrm{M} \mathrm{H}_{2} \mathrm{SO}_{4}\right)$, that leads to sample SASu, results in a slight modification of the porous structure of the SA carbon, while treatment $\mathrm{B}\left(\left(\mathrm{NH}_{4}\right)_{2} \mathrm{~S}_{2} \mathrm{O}_{8}\right.$ saturated solution in $\left.1 \mathrm{M} \mathrm{H}_{2} \mathrm{SO}_{4}\right)$, leading to sample SAS, produces a significant decrease of the adsorption capacity of the original carbon material. Such an effect can be due either to the destruction of pores, or to some blockage of the porosity by the 
abundant surface oxygen groups. This was previously reported for other carbon materials submitted to a similar treatment [28].

Table 1. Textural parameters determined from $\mathrm{N}_{2}$ adsorption isotherms (at $-196{ }^{\circ} \mathrm{C}$ ).

\begin{tabular}{cccc}
\hline Sample & $\mathbf{S}_{\text {BET }}{ }^{[\mathbf{a}]}\left(\mathbf{m}^{\mathbf{2}} \mathbf{g}^{-\mathbf{1}}\right)$ & $\mathbf{V}_{\text {micro }}{ }^{[\mathbf{b}]}\left(\mathbf{c m}^{\mathbf{3}} \mathbf{g}^{-\mathbf{1}}\right)$ & $\mathbf{V}_{\text {meso }}{ }^{[\mathrm{c}]}\left(\mathbf{c m}^{\mathbf{3}} \mathbf{g}^{-\mathbf{1}}\right)$ \\
\hline $\mathrm{SA}$ & 1464 & 0.73 & 0.74 \\
\hline $\mathrm{SASu}$ & 1522 & 0.78 & 0.60 \\
\hline $\mathrm{SAS}$ & 1274 & 0.65 & 0.48 \\
\hline $\mathrm{Ru} / \mathrm{SA}$ & 1416 & 0.71 & 0.66 \\
\hline $\mathrm{Ru} / \mathrm{SASu}$ & 1406 & 0.68 & 0.63 \\
\hline $\mathrm{Ru} / \mathrm{SAS}$ & 1218 & 0.60 & 0.47
\end{tabular}

${ }^{[\mathrm{a}]}$ BET surface area and ${ }^{[\mathrm{b}]}$ micropore volume, determined by applying the Brunauer-Emmett-Teller (BET) and the Dubinin-Radushkevich (DR) equations to the $\mathrm{N}_{2}$ adsorption data, respectively; [c] mesopore volume estimated by the difference of the volume of $\mathrm{N}_{2}$ adsorbed as liquid at $\mathrm{P} / \mathrm{P}_{0}=0.9$ and $\mathrm{P} / \mathrm{P}_{0}=0.2$.

The incorporation of Ru produces only a slight decrease of the surface area and porosity of SA, $\mathrm{SASu}$ and SAS carbons, indicating that the supported Ru nanoparticles produce almost no blockage of the carbon porosity. Thus, comparing the Ru-containing catalysts, it can be observed that $\mathrm{Ru} / \mathrm{SA}$ and $\mathrm{Ru} / \mathrm{SASu}$ show a similar porosity, somewhat higher than that of Ru/SAS.

\subsection{Surface Chemistry}

Both original and Ru-containing carbon materials were characterized by TPD. Table 2 includes the quantification of the obtained TPD profiles. The TPD-CO $\mathrm{C}_{2}$ and TPD-CO curves of the three Ru-containing catalysts are shown in Figure 1, while those corresponding to the carbon materials can be seen in Figure S4.

The evolution profiles of $\mathrm{CO}_{2}$ and $\mathrm{CO}$, produced by the decomposition of oxygen functional groups (OFG), can give information about the nature of such OFG. Those that decompose at lower temperature, mainly as $\mathrm{CO}_{2}$, have acidic character (carboxylic, anhydrides and lactones), and those that decompose as $\mathrm{CO}$ are weakly acidic, like phenol type groups, or basic, like carbonyl and quinone type groups. Based on the reported temperature intervals for the thermal decomposition of each type of group [29-32], Figure 1 shows their approximate distribution in the TPD profiles (see the figure caption for the identification of oxygen functional groups).

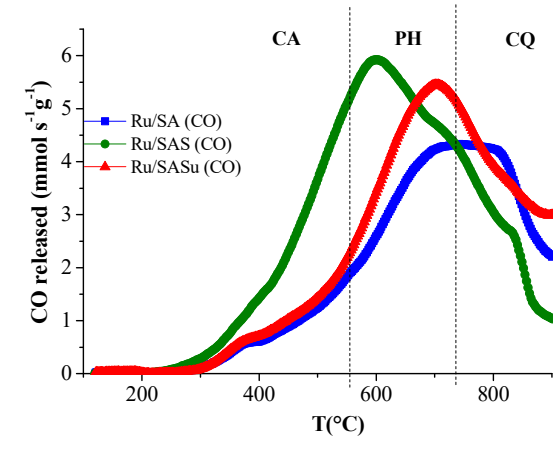

(a)

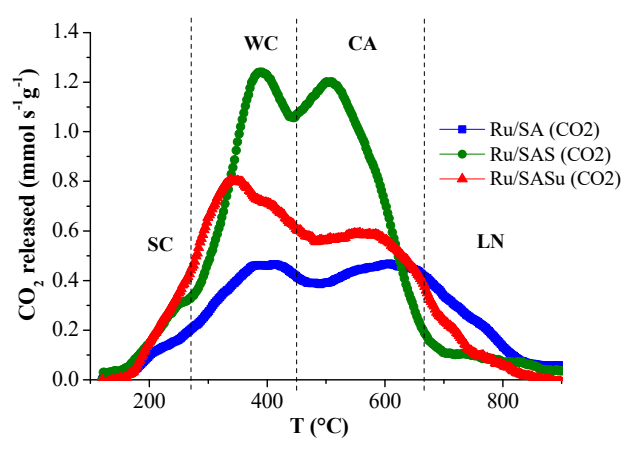

(b)

Figure 1. $\mathrm{CO}(\mathbf{a})$ and $\mathrm{CO}_{2}(\mathbf{b})$ TPD profiles for the Ru containing samples (SC: strong carboxylic acid, WA: weak carboxylic acid, CA: carboxylic anhydride acid, PH: phenol, CQ: Carbonyl and Quinone, LC: Lactone). 
Table 2. Quantification of evolved $\mathrm{CO}_{2}$ and $\mathrm{CO}$ in TPD experiments and the corresponding calculated $\mathrm{O} w \mathrm{t} \%$.

\begin{tabular}{|c|c|c|c|c|c|}
\hline Sample & $\begin{array}{c}\mathrm{CO}_{2} \\
\left(\mathrm{mmolg}^{-1}\right)\end{array}$ & $\begin{array}{c}\mathrm{CO} \\
\left(\mathrm{mmolg}^{-1}\right)\end{array}$ & $\begin{array}{l}\mathrm{CO}+\mathrm{CO}_{2} \\
\left(\mathrm{mmolg}^{-1}\right)\end{array}$ & $\begin{array}{c}\mathrm{O}^{[\mathrm{a}]} \\
(\mathbf{w t} \%)\end{array}$ & $\begin{array}{l}\text { Acidic OFG } \\
{[\mathrm{b}](\mathrm{mmol} / \mathrm{g})}\end{array}$ \\
\hline SA & 0.5 & 2.8 & 3.3 & 5.7 & 1.9 \\
\hline $\mathrm{Ru} / \mathrm{SA}$ & 0.7 & 4.5 & 5.2 & 8.6 & 2.9 \\
\hline SASu & 0.7 & 3.6 & 4.3 & 7.4 & 2.5 \\
\hline $\mathrm{Ru} / \mathrm{SASu}$ & 0.9 & 5.3 & 6.2 & 10.2 & 4.0 \\
\hline SAS & 2.2 & 6.3 & 8.5 & 14.6 & 7.2 \\
\hline $\mathrm{Ru} / \mathrm{SAS}$ & 1.2 & 6.0 & 7.2 & 11.8 & 4.5 \\
\hline
\end{tabular}

[a] determined from data of $(\mathrm{mmol} \mathrm{O}) / \mathrm{g}$ calculated as $\left.(\mathrm{mmol} \mathrm{CO}) / \mathrm{g}+(2 \mathrm{mmol} \mathrm{CO})_{2}\right) / \mathrm{g}$. Moreover, [b] determined from deconvolution data, as the sum of quantification corresponding to SC, WC, CA, $\mathrm{PH}$ and $\mathrm{LN}$ functional groups.

Pristine SA carbon has an intermediate amount of OFG compared to other activated carbon materials that have been reported in the literature, but the large content of groups that evolve as $\mathrm{CO}$ can be pointed out. It can be observed that treatment A renders a moderated amount of surface oxygen functional groups (sample SASu), while treatment B resulted, as expected, in an important development of surface functional groups (sample SAS). Thus, the sum of evolved $\mathrm{CO}_{2}$ and $\mathrm{CO}$ is, in SAS, more than double than in SASu.

A comparison of the TPD results corresponding to the carbon materials and the carbon supported $\mathrm{Ru}$ catalysts (Table 2 and Figure S4) shows that the amount of $\mathrm{CO}_{2}+\mathrm{CO}$ released from $\mathrm{Ru} / \mathrm{SA}$ and $\mathrm{Ru} / \mathrm{SASu}$ is larger than the amount released from the respective supports. This means that the preparation process of the supported Ru nanoparticles (impregnation and reduction treatment) leads to a certain restructuration of the carbon surface chemistry. This likely involves the creation of new groups and the transformation of previously existing ones [33,34]. Besides, the Ru nanoparticles can catalyze the decomposition and/or transformation of OFG during the TPD experiment and, thus, the TPD profiles are much more difficult to interpret because of that. In contrast, the evolution of $\mathrm{CO}_{2}$ and CO decreases after Ru incorporation in the SAS carbon. In this case, the net balance of the effect of the catalyst preparation steps (impregnation and reduction) is the loss of a certain amount of OFGs from the surface of the highly oxidized SAS support.

Deconvolution of the TPD curves, according to the criteria from previous works [32,35,36], was performed in order to better identify the nature of functional groups, and to try to quantify all of them (the deconvoluted curves can be seen in Figure S5). As indicated above, the main OFG are carboxylic acid (weakly (WC) and strongly (SC) acidic), carboxylic anhydride (CA), phenol (PH) and lactone (LN), with acidic character, and carbonyl and quinone (CQ), with basic character.

The calculated amount of each type of functional groups in the carbon materials and in the Ru catalysts is shown as bar diagrams in Figure 2. The experimental error in these data is below 5\%, estimated from the precision of data usually obtained in TPD experiments performed with the device used in this work.

It can be observed that, upon treatment A (sample SASu), basic CQ groups are mainly developed, followed by carboxylic anhydride (CA) groups, whereas treatment B (sample SAS) leads to an extensive development of carboxylic anhydride (CA) and phenol type (PH) groups. Regarding the effect of $\mathrm{Ru}$ incorporation, and compared to the respective supports, data of Figure 2 show that: in the case of the $\mathrm{Ru} / \mathrm{SA}$ sample, the increase in the amount of CQ groups is very important and the increase in the amount of CA and PH groups is also relevant; in Ru/SASu, the content of all types of OFG, excepting $\mathrm{SC}$ and WC increases, and in Ru/SAS, in spite of the general decrease of the OFG amount, the CQ and LN groups content increases. 


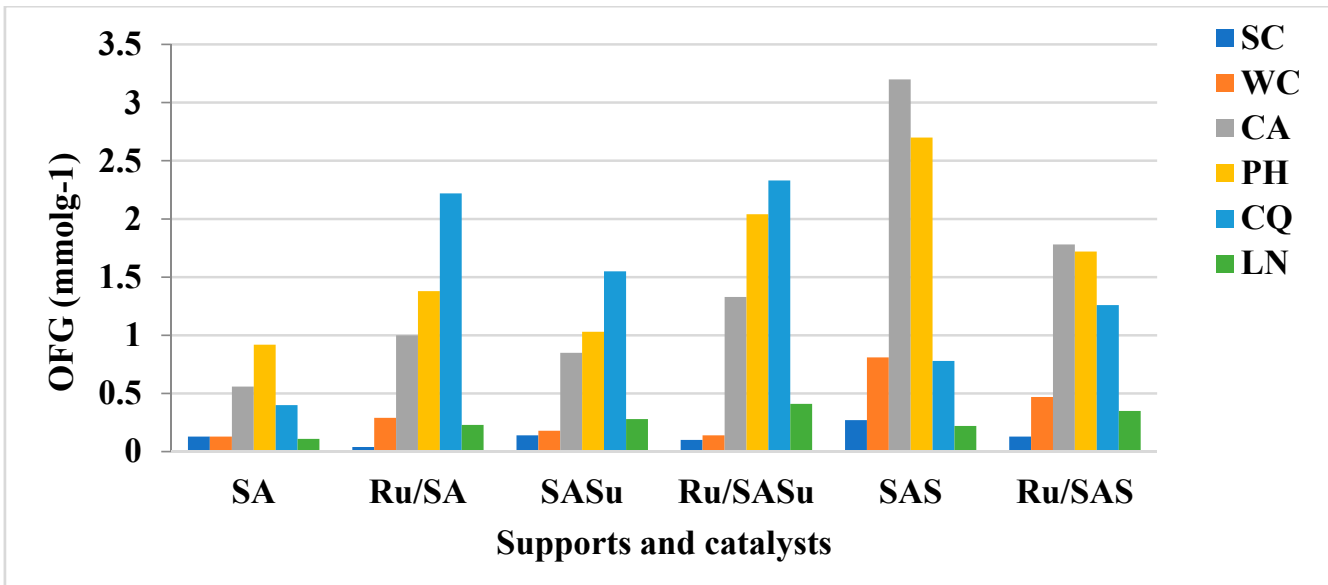

Figure 2. OFG distribution determined by deconvolution of the TPD spectra (SC: Strong acidic carboxyl, WC: Weak acidic carboxyl, CA: Carboxylic anhydride, CQ: Carbonyl or Quinone, PH: Phenol, LN: Lactone).

According to these data, the amount of acidic sites present in the studied samples has been estimated as sum of the amount of SC, WC, CA, PH and LN groups, and has been included in Table 2 . This table shows that for both, the carbon supports and the analogous metal containing catalysts, the acidic groups content follows the relative order: $\mathrm{SA}<\mathrm{SASu}<\mathrm{SAS}$.

\subsection{XPS and TEM Analysis}

XPS analysis of the three Ru containing catalysts was carried out to determine the electronic state of the supported Ru species, to identify potential sulfur species present, and to analyze the oxygen species, to complete the information obtained by TPD. Figure 3 shows the Ru 3p XPS spectra of the three studied catalysts.

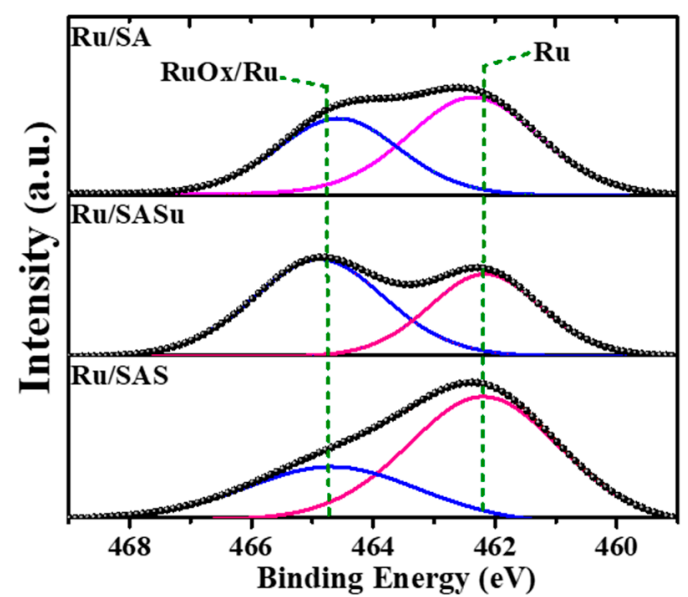

Figure 3. Ru 3p XPS spectra of the three studied catalysts.

The Ru 3p fitted spectra of the three Ru catalysts reveal the presence of metallic $\mathrm{Ru}(\mathrm{B} . \mathrm{E}=462.3 \mathrm{eV})$ [37], and oxidized $\mathrm{Ru}$ species $($ B.E. $=464.7 \mathrm{eV})[38,39]$. This means that the reduced catalysts become partially oxidized upon exposition to air, being the proportion of metallic Ru respect to total Ru close to $50 \%(56 \%, 41 \%$ and $67 \%$ in $\mathrm{Ru} / \mathrm{SA}, \mathrm{Ru} / \mathrm{SASu}$ and $\mathrm{Ru} / \mathrm{SAS}$ catalysts, respectively; the differences cannot be considered as fully significant, because the time of air exposure after the reduction treatment was not exactly the same for the three catalysts). In any case, the oxidized species will probably be reduced again to the metallic state during the reaction, because of the presence of high-pressure hydrogen at $190{ }^{\circ} \mathrm{C}$. The total amounts of Ru determined by XPS are $1.13 \mathrm{wt} \%, 1.02 \mathrm{wt} \%$ and $1.52 \mathrm{wt} \% \mathrm{in} \mathrm{Ru} / \mathrm{SA}$, $\mathrm{Ru} / \mathrm{SASu}$ and $\mathrm{Ru} / \mathrm{SAS}$, respectively, which is in line with the nominal metal loading of the catalysts. 
Figure 4 shows the O 1s XPS spectra deconvoluted according to the B.E. assignments reported in the literature $[30,40,41]$. It can be seen that they show mainly four signals corresponding to the $C=O$ bond in quinone groups (about $531.0 \pm 0.4 \mathrm{eV}$ ), $\mathrm{C}=\mathrm{O}$ or $-\mathrm{OH}$ related to lactone or hydroxyl groups $(532.0 \pm 0.2 \mathrm{eV}), \mathrm{C}-\mathrm{OH}$ attributed to phenol groups (at $533.0 \pm 0.3 \mathrm{eV})$ and $-\mathrm{COOH}(534.0 \pm 0.5 \mathrm{eV})$, assigned to carboxylic groups.

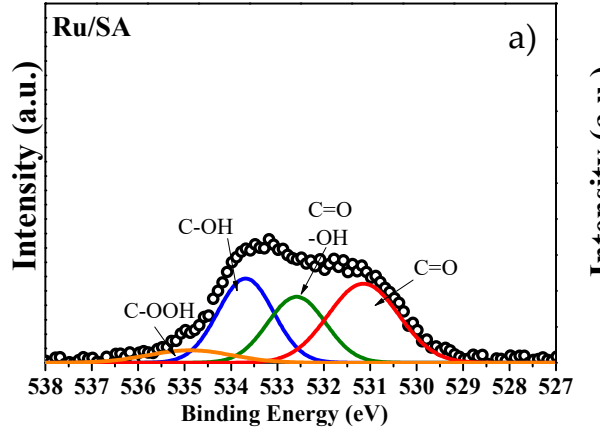
Binding Energy (eV)

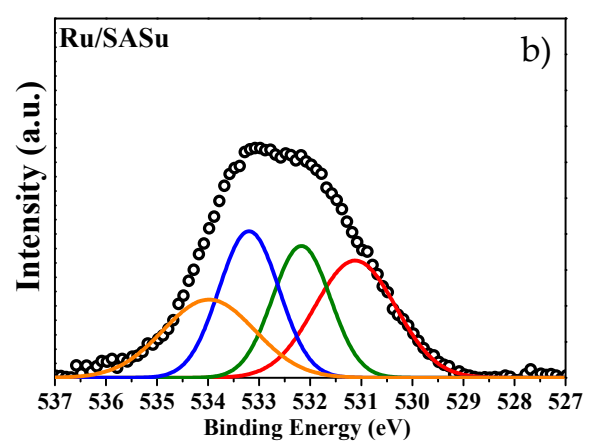

c)

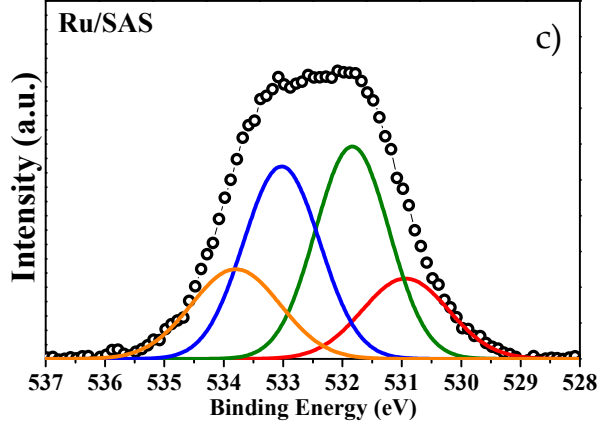

Figure 4. O 1s XPS spectra of: (a) Ru/SA, (b) Ru/SASu and (c) Ru/SAS. The code color indicated is the same in Figures $(\mathbf{a}-\mathbf{c})$.

The quantification of the O1s spectra, as oxygen wt $\%$, in all the mentioned oxygen-containing surface species, is presented in Table 3.

Table 3. Distribution of OFG as O wt\% determined from the deconvolution of the O 1s XPS peaks.

\begin{tabular}{|c|c|c|c|c|c|c|}
\hline \multicolumn{6}{|c|}{ O wt \% } & \multirow{4}{*}{$\begin{array}{l}\text { Acidic OFG } \\
\qquad(\mathrm{mmol}] \mathrm{g})\end{array}$} \\
\hline Peak & 1 & 2 & 3 & 4 & \multirow{3}{*}{$\begin{array}{c}\mathrm{O} \text { in } \\
\text { acidic } \\
\text { OFG }^{[a]}\end{array}$} & \\
\hline B.E. $(\mathrm{eV})$ & $531 \pm 0.4$ & $532 \pm 0.2$ & $533 \pm 0.3$ & $534 \pm 0.5$ & & \\
\hline Sample & $\mathrm{C}=\mathrm{O}$ & $\mathrm{C}=\mathrm{O}$ or $\mathrm{OH}$ & $\mathrm{C}-\mathrm{OH}$ & $\mathrm{C}-\mathrm{OOH}$ & & \\
\hline $\mathrm{Ru} / \mathrm{SA}$ & 3.32 & 2.26 & 2.77 & 0.62 & 3.39 & 1.93 \\
\hline $\mathrm{Ru} / \mathrm{SASu}$ & 3.63 & 2.91 & 3.36 & 2.75 & 6.11 & 2.99 \\
\hline $\mathrm{Ru} / \mathrm{SAS}$ & 3.34 & 7.51 & 7.05 & 3.83 & 10.88 & 5.60 \\
\hline
\end{tabular}

${ }^{[a]}$ sum of $\mathrm{O} w t \%$ in $\mathrm{C}-\mathrm{OH}$ and $\mathrm{C}-\mathrm{OOH}$ groups (from data in columns 3 and 4 ). ${ }^{\text {b] }}$ calculated from $\mathrm{O}$ wt. \% in $\mathrm{C}-\mathrm{OH}$ and $\mathrm{C}-\mathrm{OOH}$ groups (from data in columns 3 and 4), taking into account that column 4 corresponds to functional groups with two oxygen atoms.

Considering that the main acidic groups determined by XPS are carboxylic and phenol type ones, the $\mathrm{O} w \mathrm{t} \%$ related to these groups (columns 3 and 4 in Table 3) has been summed up and assimilated to the amount of $\mathrm{O}$ in acidic oxygen functional groups. Data show that it increases from $\mathrm{Ru} / \mathrm{SA}$ to $\mathrm{Ru} / \mathrm{SAS}$, in agreement with the TPD data. For a more proper comparison of XPS and TPD data, the amount of oxygen in acidic groups has been calculated as mmol/g of acidic groups (taking into account that column 4 corresponds to functional groups with two oxygen atoms). The calculated values are included in Table 3. Compared with analogous data of Table 2, it can be concluded that the results of both 
techniques are in line (the differences can be related with inherent differences in the fundamentals of analysis of the two techniques).

The S 2p XPS spectra of the Ru/SASu and Ru/SAS catalysts reveal the presence of sulfonic groups (peak at $\sim 168.5 \pm 0.1 \mathrm{eV}$ ) [42]. However, those spectra present a lot of noise, which makes the quantification of sulfur species quite imprecise.

Figure $5 \mathrm{a}-\mathrm{f}$ show TEM images obtained for the Ru catalysts. It must be mentioned that although, in general, well dispersed Ru nanoparticles have been observed (Figure 5a-c), some agglomeration of particles has also been found (Figure $5 \mathrm{~d}-\mathrm{f}$ ), particularly in the case of the catalyst prepared with the most oxidized support. The particle size distribution has been plotted as bar diagrams in Figure $5 \mathrm{~g}-\mathrm{i}$, being $1.3,1.4$ and $1.6 \mathrm{~nm}$ the average particle sizes in $\mathrm{Ru} / \mathrm{SA}, \mathrm{Ru} / \mathrm{SASu}$ and $\mathrm{Ru} / \mathrm{SAS}$ catalysts, respectively. Figure $\mathrm{S} 6$ shows a TEM image of the original SA activated carbon.

In general, TEM data indicate that the impregnation method used was successful for the formation of small Ru nanoparticles (average size lower than $2 \mathrm{~nm}$ ) on SA, SASu and SAS carbon materials, and it seems that the particle size slightly increases with the support oxidation. This can be related to the anchorage of the Ru precursor species on the OFG, and the effect of their partial decomposition during the reduction heat treatment, which could lead to some metal sintering [43-45].
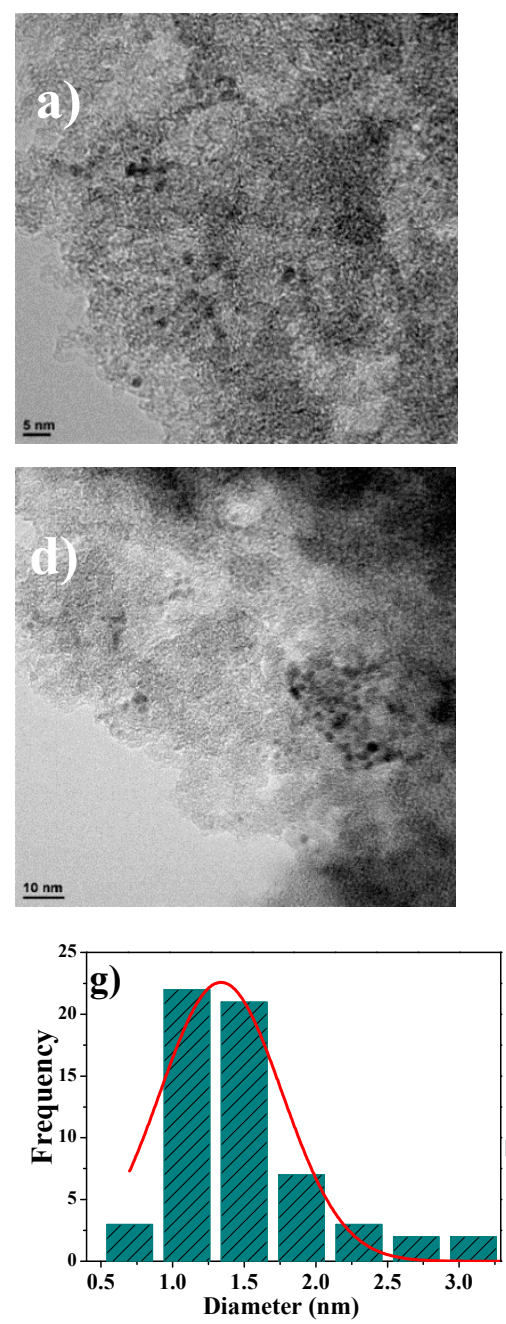
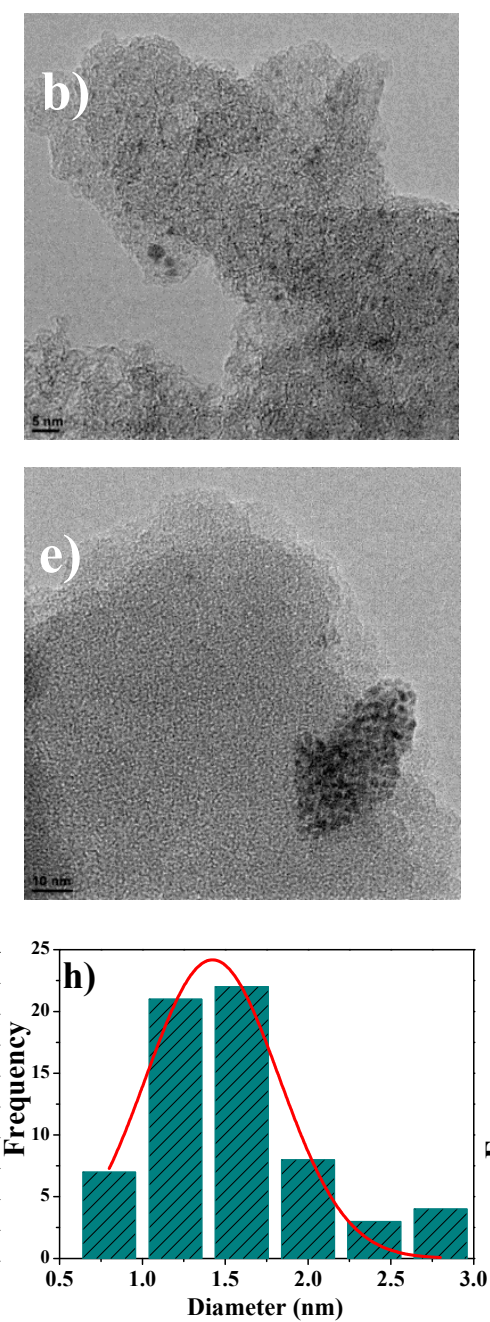
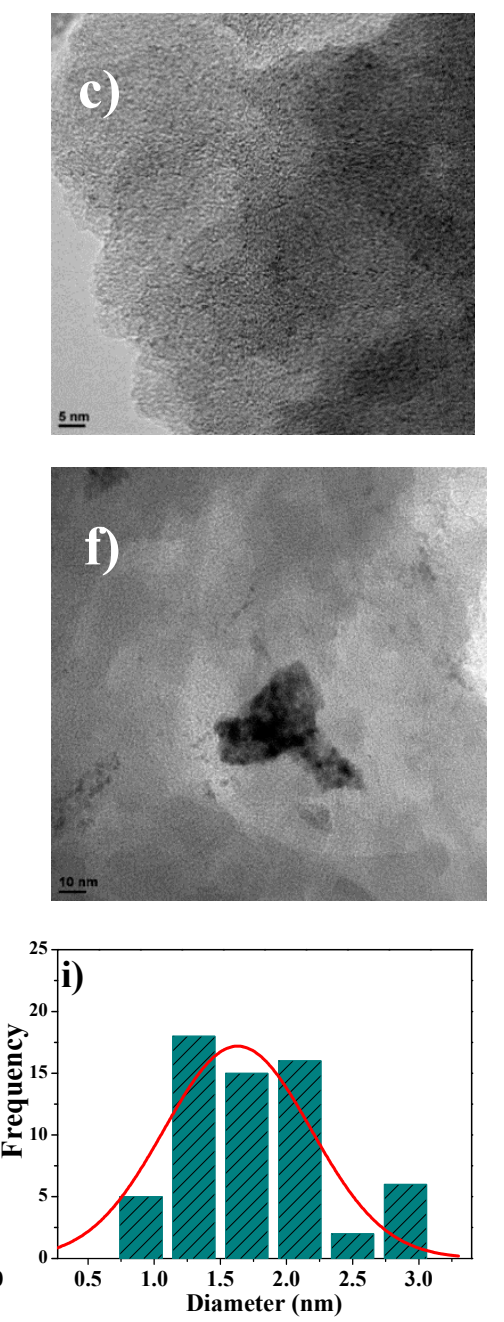

Figure 5. TEM images and Ru particle size distribution of catalysts: Ru/SA (a,d,g); Ru/SASu (b,e,h); and Ru/SAS (c,f,i). 


\subsection{Catalytic Conversion of Cellulose}

Table 4 shows the obtained cellulose conversion and yield of the main reaction products values. Other products (not shown here) have also been obtained in a very low amount, and most of them could not be identified. Figure 6 shows a simplified scheme of the reaction pathway from cellulose to the products presented in Table 4 .

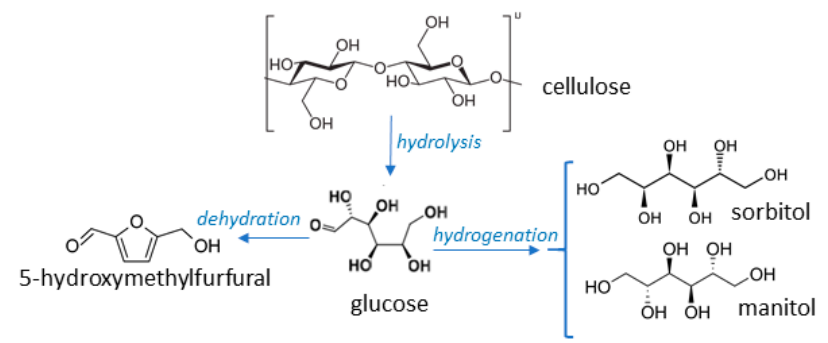

Figure 6. Scheme of the reactions and products considered in the present work.

Table 4. Cellulose conversion and products yield.

\begin{tabular}{cccccc}
\hline \multirow{2}{*}{ Catalyst } & \multirow{2}{*}{ Conversion $\%$} & \multicolumn{5}{c}{ Yield \% } \\
\cline { 3 - 6 } & & Glucose & HMF & Sorbitol & Mannitol \\
\hline Blank & 35 & 13 & 10 & - & - \\
\hline $\mathrm{Ru} / \mathrm{SA}$ & 52 & - & - & 48 & 3 \\
\hline $\mathrm{Ru} / \mathrm{SASu}$ & 46 & - & - & 35 & 1 \\
\hline $\mathrm{Ru} / \mathrm{SAS}$ & 43 & 1 & - & 33 & 1 \\
\hline Reaction conditions: $500 \mathrm{mg}$ cellulose, $125 \mathrm{mg}$ catalyst, $25 \mathrm{~mL}$ water, $190{ }^{\circ} \mathrm{C}, 50 \mathrm{bar}, 3 \mathrm{~h}$.
\end{tabular}

In the blank test (without catalyst), cellulose conversion was 35\%, and small amounts of glucose and hydroxymethylfurfural (HMF) were formed (Table 4). In the tests carried out with the carbon supported $\mathrm{Ru}$ catalysts, a noticeable increase of cellulose conversion compared with the blank experiment and a high sorbitol yield have been achieved. The experimental error in these data is below $5 \%$. It has been estimated from the deviation determined when catalytic activity tests have been repeated.

Selectivity data have been plotted in Figure 7.

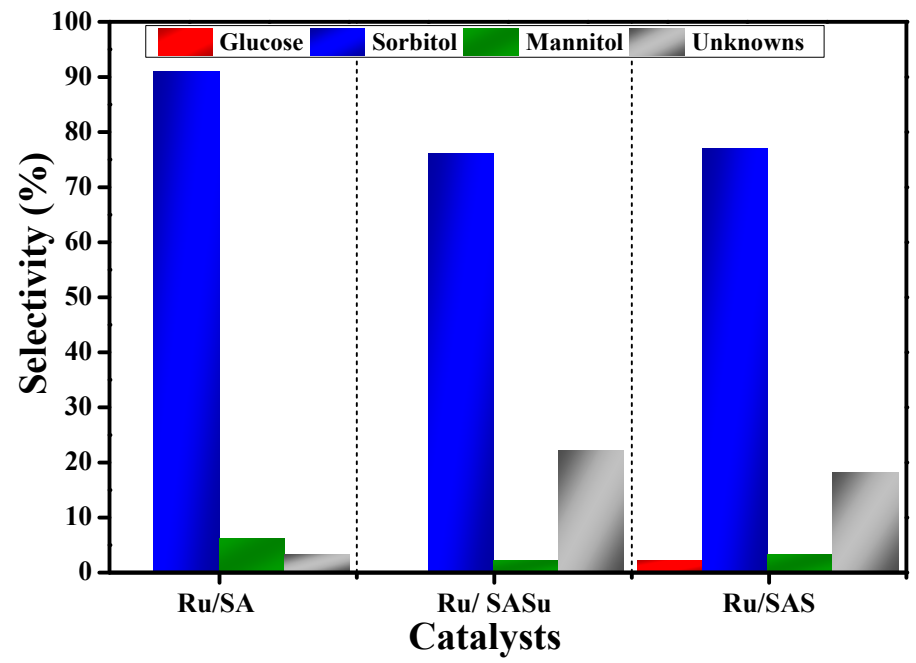

Figure 7. Selectivity data of the three studied catalysts.

Data from Table 4 show that, among the Ru containing catalysts, $\mathrm{Ru} / \mathrm{SA}$ is the best performing one in terms of cellulose conversion and sorbitol yield. As shown in Figure 7, the three catalysts are 
quite selective to sorbitol (selectivity above $75 \%$ ), being $\mathrm{Ru} / \mathrm{SA}$ highly selective (91\%). It can be pointed out that catalysts $\mathrm{Ru} / \mathrm{SASu}$ and $\mathrm{Ru} / \mathrm{SAS}$ produce a significant amount of by-products.

Catalyst $\mathrm{Ru} / \mathrm{SA}$ was tested for recyclability. After the first run, the catalyst and the unreacted cellulose were recovered from the reaction media by filtration, and after washing and drying, they were used in a second run in the same conditions (adding the necessary amount of cellulose). In the second run, cellulose conversion was $45 \%$ and selectivity to sorbitol was $73 \%$. This means that the catalyst preserves a relatively high activity and selectivity, which makes it reusable.

In a previous work dealing with the catalytic activity of SA, SASu and SAS carbons for cellulose hydrolysis [46], it was concluded that cellulose conversion and selectivity to glucose depend on the amount and type of surface OFG. In that study, the SAS carbon was found to lead to the highest cellulose conversion and glucose yield (61\% and 52\%, respectively). However, in the case of the Ru catalysts, the surface chemistry seems to have the opposite effect. As mentioned above, the presence of a high amount of OFG might lead to a less effective dispersion of the Ru particles, which could be associated with a lower activity. Moreover, some OFG, mainly those of acidic character (more abundant in $\mathrm{Ru} / \mathrm{SASu}$ and $\mathrm{Ru} / \mathrm{SAS}$ samples) may direct, likely assisted by the metal sites, the reaction to by-products through the conversion of glucose or sorbitol into other products. Furthermore, the presence of sulfonic groups, although in a low proportion, can contribute to acid catalyzed transformations that led to by-products.

Thus, in summary, the Ru/SA catalyst was found to be effective in enhancing the production of C6 polyols (sorbitol and mannitol), hindering the generation of by-products. It shows a good catalytic capability for the one pot hydrolytic hydrogenation of cellulose, similar or even higher than that shown by other catalysts reported in the literature, as some of those presented in the review work of Shrotri et al. [47] For comparison purposes, some examples of literature reported results obtained with carbon supported Ru catalysts (including reaction conditions) are summarized in Table 5 and commented on next.

Table 5. Summary of reported results in the hydrolytic hydrogenation of cellulose, using carbon supported Ru catalysts.

\begin{tabular}{cccccccccc}
\hline Entry & Cat. Name & Pret. ${ }^{[\mathbf{a}]}$ & $\mathbf{S} / \mathbf{R u}{ }^{[\mathbf{b}]}$ & $\begin{array}{c}\mathbf{T} \\
\left({ }^{\mathbf{C}} \mathbf{C}\right)\end{array}$ & $\begin{array}{c}\mathbf{P} \\
\mathbf{( B a r )}\end{array}$ & $\begin{array}{c}\mathbf{T} \\
\mathbf{( h )}\end{array}$ & $\begin{array}{c}\mathbf{X}_{\text {cellulose }} \\
\mathbf{( \% )}\end{array}$ & $\begin{array}{c}\mathbf{Y}_{\text {sorbitol }} \\
\mathbf{( \% )}\end{array}$ & Ref. \\
\hline $\mathbf{1}$ & $\mathrm{Ru} / \mathrm{BP} 2000$ & $\mathrm{BM}-2 \mathrm{~d}$ & 1620 & 190 & 50 & 24 & 86 & 37 & {$[19]$} \\
$\mathbf{2}$ & $\mathrm{Ru} / \mathrm{AC}(\mathrm{N})$ & - & 324 & 190 & 9 & 3 & 51 & 17 & {$[21]$} \\
$\mathbf{3}$ & $\mathrm{Ru} / \mathrm{AC}(\mathrm{N})$ & $\mathrm{MM}-4 \mathrm{~d}$ & 324 & 190 & 9 & 3 & 89 & 58 & {$[21]$} \\
$\mathbf{4}$ & $\mathrm{Ru} / \mathrm{CNT}$ & $\mathrm{H}_{3} \mathrm{PO}_{4}-\mathrm{MM}$ & 320 & 185 & 50 & 24 & - & 69 & {$[22]$} \\
$\mathbf{5}$ & $\mathrm{Ru} / \mathrm{MC}$ & - & 556 & 190 & 50 & 1.5 & 35.4 & 20 & {$[16]$} \\
$\mathbf{6}$ & $\mathrm{Ru} / \mathrm{CCD}$ & $\mathrm{BM}-1 \mathrm{~d}$ & 25 & 180 & 40 & 10 & 32.7 & - & {$[13]$} \\
$\mathbf{7}$ & $\mathrm{Ru} / \mathrm{CCD}-\mathrm{SO} \mathrm{H}_{3} \mathrm{H}$ & $\mathrm{BM}-1 \mathrm{~d}$ & 25 & 180 & 40 & 10 & 100 & 63.8 & {$[13]$} \\
$\mathbf{8}$ & $\mathrm{Ru} / \mathrm{AG}-\mathrm{CNT}$ & $\mathrm{BM}$ & 556 & 205 & 50 & 5 & 100 & 60.4 & {$[15]$} \\
$\mathbf{9}$ & $\mathrm{Ru} / \mathrm{SA}$ & $\mathrm{BM}-7 \mathrm{~h}$ & 400 & 190 & 50 & 3 & 52 & 48 & this work \\
\hline
\end{tabular}

[a] Cellulose pretreatment conditions; BM: ball milling, MM: Mix-milling, d: days, h: hours. ${ }^{[b]}$ Substrate/Ru ratio (mg/mg). Ru was calculated taking into account the mass of catalyst used in the experiment and the wt. \% Ru loading.

Kobayashi et al. [19] (entry 1) used a Ru catalyst supported on the BP2000 carbon black and high substrate (cellulose) to Ru ratio, and they achieved a very high cellulose conversion and an acceptable sorbitol yield but in a large reaction time ( $24 \mathrm{~h})$. Komanoya et al. [21] (entry 2) used a Ru catalyst supported on an activated carbon and reported $51 \%$ cellulose conversion and $17 \%$ sorbitol yield using a relatively low hydrogen pressure ( 9 bar). However, when these authors applied mix milling (catalyst/cellulose) pretreatment (entry 3), both conversion and selectivity strongly increased (89\% conversion and $58 \%$ sorbitol yield). This is a good result, but the long milling time (4 days) requires a lot of energy. Deng et al. [22] (entry 4) achieved a high sorbitol yield (69\%) (cellulose conversion was not reported), using $\mathrm{Ru}$ supported on carbon nanotubes as catalysts. The reaction temperature was slightly lower than in the other examples, but cellulose was pretreated with a concentrated $\mathrm{H}_{3} \mathrm{PO}_{4}$ solution, 
and the reaction time was long (24 h). In the work of Zhang et al. [16] (entry 5), Ru was supported on a mesoporous carbon, but the obtained results were relatively poor; a significant improvement (95\% cellulose conversion and 52\% sorbitol yield) was achieved combining the Ru/MC catalysts with a zirconium phosphate (1.8 g per gram of cellulose). The recent work of Li et al. [13] that deals with $\mathrm{Ru}$ catalysts supported on carbonized cassava dregs (CCD), reported the need of the carbon sulfonation to achieve a high cellulose conversion and sorbitol yield (entries 6 and 7). Conditions of the process include, among others, harsh sulfuric acid treatment of the CCD material and high catalyst dosage. Finally, Rey-Raap et al. [15] (entry 8) reported very good sorbitol yield, using catalysts supported on a hybrid carbon material prepared with a glucose derived activated carbon and carbon nanotubes. The authors used ball-milled cellulose (milling conditions not indicated), $5 \mathrm{~h}$ reaction time, and a reaction temperature higher than in other reported works.

Regarding preparation conditions, with the exception of catalysts prepared by Kobayashi et al. [19] (entry 1) that use $\mathrm{Ru}(\mathrm{NO})\left(\mathrm{NO}_{3}\right)_{3}$; in all cases, $\mathrm{RuCl}_{3}$ has been used as $\mathrm{Ru}$ precursor. Additionally, like in the present work, impregnation has been the general preparation procedure employed. It can be mentioned that, in the case of catalysts presented in entries 2 to 7 , the catalysts reduction treatment temperature is higher than in the present work $\left(300,350\right.$ or $400{ }^{\circ} \mathrm{C}$, vs. $\left.250{ }^{\circ} \mathrm{C}\right)$, Rey-Raap et al. [15] also reduced the catalysts at $250^{\circ} \mathrm{C}$, and in the work of Kobayashi et al. [19], the catalysts were reduced at $180{ }^{\circ} \mathrm{C}$, but suspended in water and under $4 \mathrm{MPa} \mathrm{H}_{2}$, being then collected by filtration and dried, which adds some steps to the preparation process.

Some of the studies reported in Table 5 include reusability tests. After reaction, Li et al. [13] separated the mixture of catalyst and unreacted cellulose from the solution, and after washing and drying, fresh cellulose was added to start a second run. They repeated the process for up to five recycles, and found about a 10\% decrease in sorbitol yield [13]. A slight sorbitol yield decrease (3\%) was also observed by Komanoya et al. [21] in three reusing experiment tests, and Deng et al. [22] also found a decrease of the sorbitol yield (10\%), especially after the first reuse. This behaviour is similar to the one found for the Ru/SA catalysts of the present work, in which sorbitol yield in the second run was about 15\% lower than in the first one. However, Rey-Raap et al. [15] report very good reusability of their Ru catalyst supported on a hybrid carbon material (sorbitol yield kept above 60\%).

To summarize, some interesting conclusions can be extracted, comparing our results with those dealing with carbon-based catalysts previously published. For example, the sorbitol yield obtained in the present work is higher, and it has been obtained in a much shorter time than in the study reported by Kobayashi et al. [19] (entry 1). The high cellulose conversion and the much lower sorbitol yield obtained by these authors indicate that their process is not very selective. The good results obtained by Komanoya et al. [21] (entry 3) require, as already mentioned, four days' mix-milling and, comparing the results of the present work with those of Deng et al. [22] (entry 4), a higher sorbitol yield has been obtained avoiding acid cellulose pretreatment, in a shorter reaction time and with a higher S/Ru ratio. The good results of Rey-Raap et al. [15] (entry 8) are undoubtedly very interesting, but compared with the present work, they have a required higher temperature and reaction time.

This comparison allows concluding that the catalysts prepared in this work are competitive in relation to other catalysts developed for the hydrolytic hydrogenation of cellulose, pointing out that both the catalysts' preparation and the reaction conditions used are mild, and can be considered as environmentally friendly.

\section{Conclusions}

The combined hydrolytic hydrogenation of cellulose into sorbitol was successfully achieved using catalysts prepared by supporting $\mathrm{Ru}$ nanoparticles $(1 \mathrm{wt} \% \mathrm{Ru})$ on mesoporous carbon materials (the commercial activated carbon SA, and SASu and SAS carbons, both obtained by SA functionalization). The sulfonation treatment creates a moderated amount of oxygen functional groups on the carbon surface, and only a slight modification of the porous structure of the SA carbon. On the other hand, the oxidation treatment leads to an important development of surface functional groups, and a 
significant decrease in the adsorption capacity. Besides, the amount and type of the surface functional groups of the carbon materials becomes modified as a result of the Ru incorporation process. In spite of these modifications, it has been concluded that the mesopore volume remains high in the three catalysts. The Ru nanoparticles are small and well dispersed, and about $50 \% \mathrm{Ru}$ is present in zero valent state even after air exposition of the catalysts.

The three catalysts exhibited high cellulose conversion and very good selectivity to sorbitol under relatively mild reaction conditions. The $\mathrm{Ru} / \mathrm{SA}$ catalyst is the best performing one, with $52 \%$ cellulose conversion and a very high sorbitol selectivity (91\%). The differences in surface chemistry seem to determine the observed differences in the catalytic behavior, and although a positive effect of a large amount of acidic OFG was foreseen, the results allow one to conclude that in the Ru containing catalysts, such groups can catalyze the formation of by-products, and are responsible for lower selectivity.

The findings of this study highlight the performance of the $\mathrm{Ru} / \mathrm{SA}$ catalyst in the one pot hydrolytic hydrogenation of cellulose, which surpasses those of many other bifunctional catalysts. Moreover, it can be pointed out that both the catalyst preparation and the reaction conditions used in this work can be regarded as economically convenient and environmentally friendly.

Supplementary Materials: The following are available online at http://www.mdpi.com/1996-1073/13/17/4394/s1, Figure S1. Reactor scheme, Figure S2. Example of HPLC data obtained in the catalytic activity experiment carried out with the $\mathrm{Ru} / \mathrm{SA}$ catalyst, Figure $\mathrm{S} 3 . \mathrm{N}_{2}$ adsorption isotherms at $-196^{\circ} \mathrm{C}$ of the carbon supports and Ru catalysts, Figure S4. TPD profiles for supported Ru on carbon catalysts and carbons support, Figure S5. Deconvolution of the TPD profiles obtained for the supported Ru catalysts (SC: Strong acidic carboxyl groups, WC: Weak acidic carboxyl groups, CA: Carboxylic anhydride groups, CQ: Carbonyls or Quinones, PH: Phenol, LN: Lactones). Figure S6. TEM image of the SA activated carbon.

Author Contributions: Conceptualization, M.C.R.-M., M.Á.L.-R. and F.-Z.A.; methodology, M.C.R.-M., M.Á.L.-R. and F.-Z.A.; validation, M.C.R.-M., M.Á.L.-R. and F.-Z.A.; formal analysis, F.-Z.A.; investigation, F.-Z.A.; data curation, M.C.R.-M., M.Á.L.-R. and F.-Z.A.; writing-Original draft preparation, F.-Z.A.; writing-Review and editing, M.C.R.-M. and M.Á.L.-R.; supervision, M.C.R.-M. and M.Á.L.-R.; project administration, M.C.R.-M. and M.Á.L.-R.; funding acquisition, M.C.R.-M. and M.Á.L.-R. All authors have read and agreed to the published version of the manuscript.

Funding: This research was funded by Spanish Ministry of Science, Innovation and Universities and FEDER, project of reference RTI2018-095291-B-I00, GV/FEDER (PROMETEO/2018/076) and University of Alicante (VIGROB-136).

Acknowledgments: The authors thank funding to the Spanish Ministry of Science, Innovation and Universities and FEDER, project of reference RTI2018-095291-B-I00, GV/FEDER (PROMETEO/2018/076) and University of Alicante (VIGROB-136) for financial support. F.-Z. Azar thanks the AECID (research scholarship for development (2015/2016)) and University of Alicante (cooperation programs for development) for financial support.

Conflicts of Interest: The authors declare no conflict of interest. The funders had no role in the design of the study; in the collection, analyses, or interpretation of data; in the writing of the manuscript, or in the decision to publish the results.

\section{References}

1. Satinder, K.B.; Saurabh, J.S.; Kannan, P. Platform Chemical Biorefinery. Future Green Industry; Brar, S.K., Sarma, S.J., Pakshirajan, K., Eds.; Elsevier: Amsterdam, The Netherlands, 2017; ISBN 9780128029800.

2. Fang, Z.; Smith, R.L., Jr.; Li, H. (Eds.) Production of Biofuels and Chemicals with Bifunctional Catalysts; Springer: Berlin/Heidelberg, Germany, 2017.

3. De Wild, P.; Reith, H.; Heeres, E. Biomass pyrolysis for chemicals. Biofuels 2011, 2, 185-208. [CrossRef]

4. Sheldon, R.A. Green and sustainable manufacture of chemicals from biomass: State of the art. Green Chem. 2014, 16, 950-963. [CrossRef]

5. Paone, E.; Tabanelli, T.; Mauriello, F. The rise of lignin biorefinery. Curr. Opin. Green Sustain. Chem. 2020, 24, 1-6. [CrossRef]

6. Vilcocq, L.; Cabiac, A.; Especel, C.; Guillon, E.; Duprez, D. Transformation of sorbitol to biofuels by heterogeneous catalysis: Chemical and industrial considerations. Oil Gas Sci. Technol.-Rev. d'IFP Energies Nouv. 2013, 68, 841-860. [CrossRef]

7. Awuchi, C.G. Sugar alcohols: Chemistry, production, health concerns and nutritional importance of mannitol, sorbitol, xylitol, and erythritol. Int. J. Adv. Acad. Res. Sci. Technol. Eng. 2017, 3, 31-66. 
8. Brar, S.K.; Sarma, S.J.; Pakshijaran, K. Sorbitol production from biomass and its global market. In Platform Chemical Biorefinery; Elsevier: Amsterdam, The Netherlands, 2016; pp. 217-227.

9. Van de Vyver, S.; Geboers, J.; Jacobs, P.A.; Sels, B.F. Recent advances in the catalytic conversion of cellulose. ChemCatChem 2011, 3, 82-94. [CrossRef]

10. Besson, M.; Gallezot, P.; Pinel, C. Conversion of biomass into chemicals over metal catalysts. Chem. Rev. 2014, 114, 1827-1870. [CrossRef]

11. Rinaldi, R.; Schüth, F. Design of solid catalysts for the conversion of biomass. Energy Environ. Sci. 2009, 2, 610-626. [CrossRef]

12. Huang, Y.-B.; Fu, Y. Hydrolysis of cellulose to glucose by solid acid catalysts. Green Chem. 2013, 15, $1095-1111$. [CrossRef]

13. Li, Z.; Liu, Y.; Liu, C.; Wu, S.; Wei, W. Direct conversion of cellulose into sorbitol catalyzed by a bifunctional catalyst. Bioresour. Technol. 2019, 274, 190-197. [CrossRef]

14. Gromov, N.V.; Medvedeva, T.B.; Taran, O.P.; Timofeeva, M.N.; Said-Aizpuru, O.; Panchenko, V.N.; Gerasimov, E.Y.; Kozhevnikov, I.V.; Parmon, V.N. The main factors affecting the catalytic properties of Ru/Cs-HPA systems in one-pot hydrolysis-hydrogenation of cellulose to sorbitol. Appl. Catal. A Gen. 2020, 595, 117489. [CrossRef]

15. Rey-Raap, N.; Ribeiro, L.S.; Órfão, J.J.d.M.; Figueiredo, J.L.; Pereira, M.F.R. Catalytic conversion of cellulose to sorbitol over Ru supported on biomass-derived carbon-based materials. Appl. Catal. B Environ. 2019, 256, 117826. [CrossRef]

16. Zhang, G.; Chen, T.; Zhang, Y.; Liu, T.; Wang, G. Effective Conversion of Cellulose to Sorbitol Catalyzed by Mesoporous Carbon Supported Ruthenium Combined with Zirconium Phosphate. Catal. Lett. 2020, 150, 2294-2303. [CrossRef]

17. Arunajatesan, V.; Chen, B.; Möbus, K.; Ostgard, D.J.; Tacke, T.; Wolf, D. Carbon-Supported Catalysts for the Chemical Industry. In Carbon Materials for Catalysis; Serp, P., Figueiredo, J.L., Eds.; John Wiley \& Sons Inc.: Hoboken, NJ, USA, 2009; pp. 535-572, ISBN 9780470178850.

18. Besson, M.; Gallezot, P.; Perrard, A.; Pinel, C. Active carbons as catalysts for liquid phase reactions. Catal. Today 2005, 102-103, 160-165. [CrossRef]

19. Kobayashi, H.; Ito, Y.; Komanoya, T.; Hosaka, Y.; Dhepe, P.L.; Kasai, K.; Hara, K.; Fukuoka, A. Synthesis of sugar alcohols by hydrolytic hydrogenation of cellulose over supported metal catalysts. Green Chem. 2011, 13, 326-333. [CrossRef]

20. Manaenkov, O.V.; Kislitsa, O.V.; Matveeva, V.G.; Sulman, E.M.; Sulman, M.G.; Bronstein, L.M. Cellulose Conversion Into Hexitols and Glycols in Water: Recent Advances in Catalyst Development. Front. Chem. 2019, 7, 834. [CrossRef]

21. Komanoya, T.; Kobayashi, H.; Hara, K.; Chun, W.J.; Fukuoka, A. Kinetic study of catalytic conversion of cellulose to sugar alcohols under low-pressure hydrogen. ChemCatChem 2014, 6, 230-236. [CrossRef]

22. Deng, W.; Tan, X.; Fang, W.; Zhang, Q.; Wang, Y. Conversion of cellulose into sorbitol over carbon nanotube-supported ruthenium catalyst. Catal. Lett. 2009, 133, 167-174. [CrossRef]

23. Ribeiro, L.S.; Delgado, J.J.; Órfão, J.J.M.; Pereira, M.F.R. Carbon supported Ru-Ni bimetallic catalysts for the enhanced one-pot conversion of cellulose to sorbitol. Appl. Catal. B Environ. 2017, 217, 265-274. [CrossRef]

24. Chung, P.-W.; Charmot, A.; Click, T.; Lin, Y.; Bae, Y.; Chu, J.-W.; Katz, A. Importance of Internal Porosity for Glucan Adsorption in Mesoporous Carbon Materials. Langmuir 2015, 31, 7288-7295. [CrossRef]

25. Rodríguez-Reinoso, F.; Linares-Solano, Á. Microporous structure of activated carbon as revealed by adsorption methods. In Chemistry and Physics of Carbon; Marcel Dekker Inc.: New York, NY, USA, 1989; Volume 21, pp. 1-146.

26. Rouquerol, F.; Rouquerol, J.; Sing, K. Adsorption by Powders E Porous Solids-Principles, Methodology and Applications; Academic Press: London, UK, 1999.

27. Thommes, M.; Kaneko, K.; Neimark, A.V.; Olivier, J.P.; Rodríguez-Reinoso, F.; Rouquerol, J.; Sing, K.S.W. Physisorption of gases, with special reference to the evaluation of surface area and pore size distribution (IUPAC Technical Report). Pure Appl. Chem. 2015, 87, 1051-1069. [CrossRef]

28. Rufete-Beneite, M.; Román-Martínez, M.C.; Linares-Solano, A. Insight into the immobilization of ionic liquids on porous carbons. Carbon 2014, 77, 947-957. [CrossRef]

29. Figueiredo, J.L.; Pereira, M.F.R.; Freitas, M.M.A.; Órfão, J.J.M. Modification of the surface chemistry of activated carbons. Carbon 1999, 37, 1379-1389. [CrossRef] 
30. Zhou, J.-H.; Sui, Z.-J.; Zhu, J.; Li, P.; Chen, D.; Dai, Y.-C.; Yuan, W.-K. Characterization of surface oxygen complexes on carbon nanofibers by TPD, XPS and FT-IR. Carbon 2007, 45, 785-796. [CrossRef]

31. Silva, A.M.T.; Machado, B.F.; Figueiredo, J.L.; Faria, J.L. Controlling the surface chemistry of carbon xerogels using $\mathrm{HNO}_{3}$-hydrothermal oxidation. Carbon 2009, 47, 1670-1679. [CrossRef]

32. Li, N.; Ma, X.; Zha, Q.; Kim, K.; Chen, Y.; Song, C. Maximizing the number of oxygen-containing functional groups on activated carbon by using ammonium persulfate and improving the temperature-programmed desorption characterization of carbon surface chemistry. Carbon 2011, 49, 5002-5013. [CrossRef]

33. Adsuar-García, M.D.; Flores-Lasluisa, J.X.; Azar, F.Z.; Román-Martínez, M.C. Carbon-black-supported Ru catalysts for the valorization of cellulose through hydrolytic hydrogenation. Catalysts 2018, 8, 572. [CrossRef]

34. Machado, B.F.; Oubenali, M.; Rosa Axet, M.; Trang Nguyen, T.; Tunckol, M.; Girleanu, M.; Ersen, O.; Gerber, I.C.; Serp, P. Understanding the surface chemistry of carbon nanotubes: Toward a rational design of Ru nanocatalysts. J. Catal. 2014, 309, 185-198. [CrossRef]

35. Szymański, G.S.; Karpiński, Z.; Biniak, S.; Światkowski, A. The effect of the gradual thermal decomposition of surface oxygen species on the chemical and catalytic properties of oxidized activated carbon. Carbon 2002, 40, 2627-2639. [CrossRef]

36. Figueiredo, J.L.; Pereira, M.F.R.; Freitas, M.M.A.; Órfão, J.J.M. Characterization of active sites on carbon catalysts. Ind. Eng. Chem. Res. 2007, 46, 4110-4115. [CrossRef]

37. Folkesson, B. ESCA Studies on the charge distribution in some dinitrogen complexes of Rhenium, Iridium, Ruthenium, and Osmium. Acta Chem. Scand. 1973, 27, 287-302. [CrossRef]

38. Shen, J.Y.; Adnot, A.; Kaliaguine, S. An ESCA study of the interaction of oxygen with the surface of ruthenium. Appl. Surf. Sci. 1991, 51, 47-60. [CrossRef]

39. KÖtz, R. XPS Studies of Oxygen Evolution on Ru and RuO2 Anodes. J. Electrochem. Soc. 1983, 130, 825-829. [CrossRef]

40. Oh, Y.J.; Yoo, J.J.; Kim, Y.I.; Yoon, J.K.; Yoon, H.N.; Kim, J.-H.; Park, S. Bin Oxygen functional groups and electrochemical capacitive behavior of incompletely reduced graphene oxides as a thin-film electrode of supercapacitor. Electrochim. Acta 2014, 116, 118-128. [CrossRef]

41. Velo-Gala, I.; López-Peñalver, J.J.; Sánchez-Polo, M.; Rivera-Utrilla, J. Surface modifications of activated carbon by gamma irradiation. Carbon 2014, 67, 236-249. [CrossRef]

42. Lin, Z.; Cai, X.; Fu, Y.; Zhu, W.; Zhang, F. Cascade catalytic hydrogenation-cyclization of methyl levulinate to form $\mathrm{g}$-valerolactone over Ru nanoparticles supported on a sulfonic acid-functionalized UiO-66 catalyst. RSC Adv. 2017, 7, 44082-44088. [CrossRef]

43. Li, H.-X.; Zhang, X.; Wang, Q.; Zhang, K.; Cao, Q.; Jin, L. Preparation of the recycled and regenerated mesocarbon microbeads-based solid acid and its catalytic behaviors for hydrolysis of cellulose. Bioresour. Technol. 2018, 270, 166-171. [CrossRef]

44. Peng, G.; Gramm, F.; Ludwig, C.; Vogel, F. Effect of carbon surface functional groups on the synthesis of $\mathrm{Ru} / \mathrm{C}$ catalysts for supercritical water gasification. Catal. Sci. Technol. 2015, 5, 3658-3666. [CrossRef]

45. Román-Martínez, M.C.; Cazorla-Amorós, D.; Linares-Solano, A.; De Lecea, C.S.-M.; Yamashita, H.; Anpo, M. Metal-support interaction in $\mathrm{Pt} / \mathrm{C}$ catalysts. Influence of the support surface chemistry and the metal precursor. Carbon 1995, 33, 3-13. [CrossRef]

46. Azar, F.-Z.; Lillo-Ródenas, M.A.; Román-Martínez, M.C. Cellulose hydrolysis catalysed by mesoporous activated carbons functionalized under mild conditions. SN Appl. Sci. 2019, 1, 1739. [CrossRef]

47. Shrotri, A.; Kobayashi, H.; Fukuoka, A. Cellulose Depolymerization over Heterogeneous Catalysts. Acc. Chem. Res. 2018, 51, 761-768. [CrossRef] [PubMed]

(C) 2020 by the authors. Licensee MDPI, Basel, Switzerland. This article is an open access article distributed under the terms and conditions of the Creative Commons Attribution (CC BY) license (http://creativecommons.org/licenses/by/4.0/). 